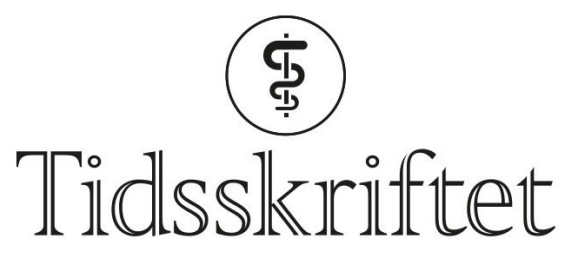

DEN NORSKE LEGEFORENING

\title{
Å gjenkjenne galskap
}

ESSAY

\section{PÅL GJERDEN}

E-post: pal.gjerden@sthf.no

Pål Gjerden er dr.philos. og overlege ved Ambulant team, DPS Nedre Telemark, Skien og har primært arbeidet med psykoseproblematikk.

Forfatteren har fylt ut ICMJE-skjemaet og oppgir ingen interessekonflikter.

\section{LARS SLØRDAL}

Lars Slørdal er professor i farmakologi ved NTNU og overlege ved St. Olavs hospital. Forfatteren har fylt ut ICMJE-skjemaet og oppgir ingen interessekonflikter.

Hva er galskap? Kan vi beskrive og gjenkjenne galskap? Hvis ikke, er det da meningsfullt å snakke om psykiatrisk diagnostikk som et fag? 


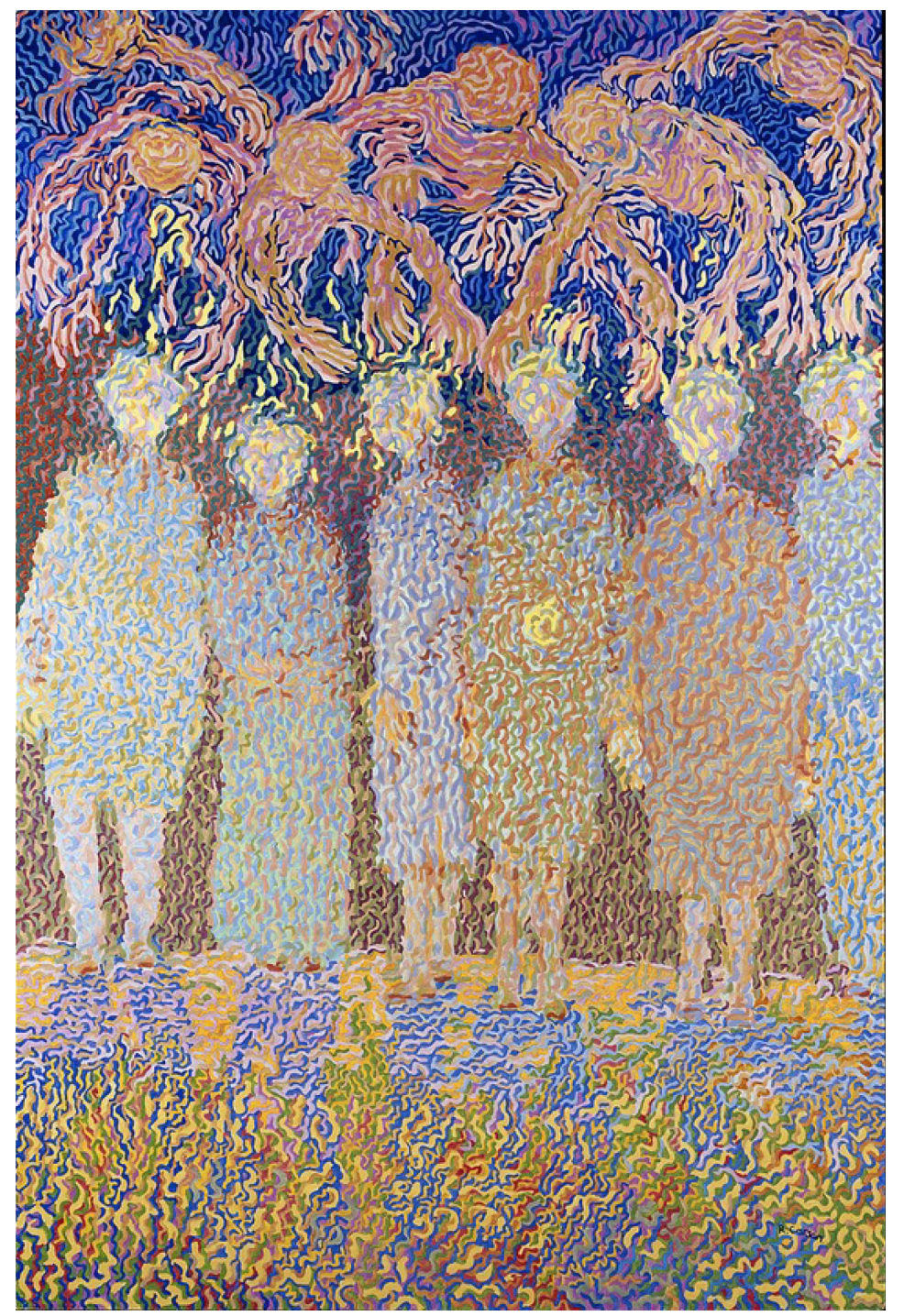

Patients Waiting to See the Doctor, with Figures Representing Their Fears malt av Rosemary Carson (f.1962) $i$ 1997. Carson ble diagnostisert med schizofreni da hun var 15 år. Dette ledet til flere opphold på mentalsykehus, som nå er hennes inspirasjon for verkene. Foto: Welcome Library

Overgangen fra en psykologisk og individuell forståelse av psykisk lidelse til en biologisk og kriteriebasert diagnostikk er et av de klareste veiskillene i psykiatriens historie.

Paradigmeskiftet skjedde relativt raskt og ble for alvor slått fast med innføringen av diagnosesystemet DSM-III i 1980. Diagnostic and Statistical Manual of Mental Disorders (DSM) er det dominerende klassifikasjonssystemet for psykiske lidelser. Det eies av den amerikanske psykiaterforeningen, som er en privat interesseorganisasjon. Den første utgaven kom i 1952, og nåværende utgave er den sjette i rekken.

I 1960- og 70-årene var psykiatrifaget under press. I spissen stod antiautoritære 68-ere. Inspirert av både jobb som nattevakt og deltakelse i forskjellige eksperimenter med psykoaktive stoffer ved Menlo Park Veterans' Administration Hospital i San Fransisco publiserte Ken Kesey i 1962 romanen One flew over the cuckoo's nest, på norsk kjent som Gjøkeredet. Filmatiseringen fra 1975 med Jack Nicholson i hovedrollen som den etter hvert lobotomerte McMurphy hadde stor gjennomslagskraft og ga et sjokkerende bilde av en umenneskelig institusjonspsykiatri. Kritikken kom dessuten ikke bare utenfra;

psykiatrifaget favnet meningsbærende «antipsykiatere» med betydelig innflytelse, slik som Ronald David Laing og Thomas Szasz.

\section{Oppsiktsvekkende artikkel}

David Rosenhan (1929-2012) var professor i både jus og psykologi ved Stanford University og var sannsynligvis påvirket av både Laing og Szasz. I 1969, muligens i et forsøk på å tilegne seg erfaringer for å forbedre studentundervisningen, fikk han seg selv innlagt som pasient i et 
psykiatrisk sykehus under pseudonym og med falske symptomer. Egenerfaringene førte angivelig til at flere ble trukket med; Rosenhan fikk etter hvert åtte andre medarbeidere og bekjente til å gå inn i roller som psykiatriske pasienter. Dette resulterte i artikkelen «On being sane in insane places», publisert i Science i 1973 (1). Artikkelen ble en av psykiatrihistoriens mest omtalte og omdiskuterte enkeltpublikasjoner.

Rosenhans artikkel fra 1971 syntes å vise at psykiatere ikke engang klarte å skille mellom schizofrene pasienter og friske mennesker

Det var allerede kjent at amerikanske og britiske psykiatere brukte schizofrenibegrepet ulikt. En stor studie fra 1971 viste at sannsynligheten for at psykiatere på hver sin side av Atlanterhavet stilte samme diagnose på samme pasient var under 50 \% (2). Det nye og oppsiktsvekkende med Rosenhans artikkel var at den syntes å vise at psykiatere ikke engang klarte å skille mellom schizofrene pasienter og friske mennesker. Dette oppsiktsvekkende funnet var en viktig pådriver i forsøket på å utvikle en mer presis diagnostikk.

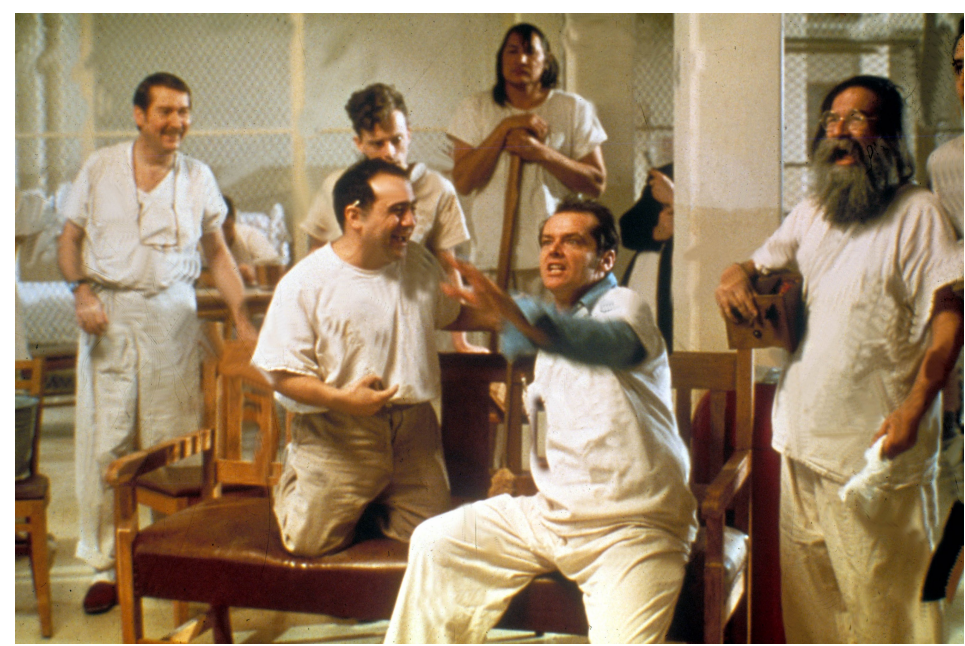

Gjøkeredet med Jack Nicholson i hovedrollen. Foto: Shutterstock editorial / NTB

Ifølge Rosenhans artikkel la åtte friske frivillige (i framstillingen kalt pseudopasienter) seg på eget initiativ inn på 12 psykiatriske sykehus i fem amerikanske delstater. Alle rapporterte diffuse hallusinasjoner ved innleggelsen, og alle skulle i henhold til Rosenhans protokoll oppføre seg normalt under oppholdet. En pasient ble utskrevet med en manisk-depressiv diagnose, resten fikk en schizofrenidiagnose. Alle ble tungt medisinert. En niende pasient ble utelatt fra studien, angivelig fordi han ikke holdt seg til forskningsprotokollen.

Trass i all oppmerksomheten rundt Science-artikkelen publiserte Rosenhan aldri noe mer om dette temaet. Han begynte å arbeide med et bokmanuskript, som ikke ble sluttført. I resten av sin karriere publiserte han artikler over et vidt interessefelt, fra altruisme til studier av psykiske reaksjoner etter jordskjelv.

\section{Avslørende bok}

I en nylig utgitt bok, The great pretender (3), ettergår forfatteren Susannah Cahalan Rosenhans funn. Hun sannsynliggjør at Science-artikkelen (1), og dermed noen av argumentene bak utviklingen i psykiatri og psykiatrisk diagnostikk slik faget utøves i dag, rett og slett bygger på forskningsjuks. Hun antyder også at ledende personer i utviklingen av DSM-III har vært klar over dette. 


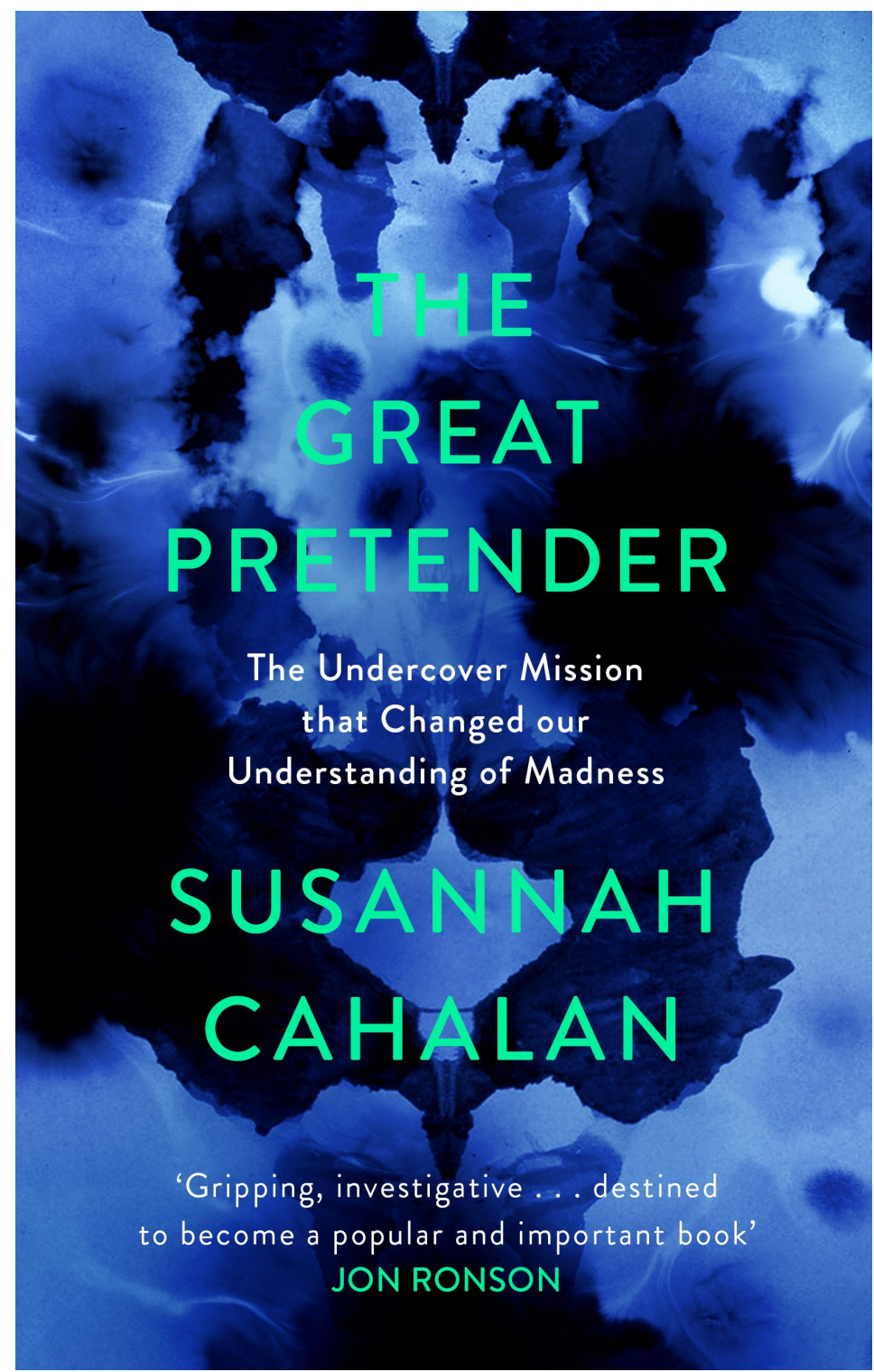

Aktuell bok: Susannah Cahalan. The great pretender. The undercover mission that changed our understanding of madness. Edinburgh: Canongate Books, 2020.

Cahalan har et selvopplevd og kritisk utgangspunkt. I en tidligere bok (4) har hun beskrevet hvordan en autoimmun encefalitt gjorde henne psykotisk og at hun så vidt unngikk en schizofrenidiagnose. Under arbeid med den siste boken ble hun på eget initiativ diagnostisert ved hjelp av et strukturert intervju avledet fra DSM-5 (SCID), utført av Michael First, en av hovedforfatterne bak SCID. Hennes symptombilde under sykdomsperioden oppfylte DSM-kriterier for en schizofreniform lidelse, definert som schizofreni av mindre enn seks måneders varighet. I rettferdighetens navn innså First at diagnosen ikke var riktig, men bare fordi fasiten, autoimmun encefalitt, forelå.

Utviklingen av diagnosesystemene har ikke bedret verken diagnostisk konsensus eller treffsikkerhet

I arbeidet med den nye boken har Cahalan skaffet seg tilgang til Rosenhans private arkiv. I dette materialet ble alle de åtte pseudopasientene kort omtalt, men under pseudonym. Det var tydelig at den første av dem, «David Laurie», var Rosenhan selv. Letingen etter de andre ble vanskeligere enn Cahalan hadde sett for seg. I løpet av fem år oppsøkte hun alle de samarbeidspartnere, studenter, familie, venner og kolleger hun kunne finne. Grundig leting i arkiver og pasientjournaler, samtaler med komparenter og til dels med aktører, annonsering i fagtidsskrifter og andre anstrengelser resulterte i identifisering av kun to andre pseudopasienter.

Rosenhans egne beskrivelser kunne kontrolleres. Hans journal fra Haverford State Hospital 
var tilgjengelig for Cahalan og framviste et bilde som i omfang og alvorlighetsgrad var vesentlig annerledes enn det han formidlet i Science-artikkelen. Han hevdet å sitere ordrett fra sin journal, men flere påstander i artikkelen var rent oppspinn, og viktig informasjon fra journalen ble utelatt eller ikke korrekt gjengitt. Avvikene omfattet blant annet lengde og alvorlighetsgrad av symptomer, suicidale tanker, varighet av sykehusoppholdet og behandlende leges vurdering ved utskriving.

Den ene av de to øvrige pseudopasientene beskrev innleggelsen negativt, mens den andre, som ble utelatt fra den endelige artikkelen, omtalte sykehusoppholdet som en positiv erfaring. Cahalan lyktes ikke med å identifisere noen av de øvrige seks pseudopasientene, selv om alle angivelig tilhørte Rosenhans omgangskrets og var kortfattet beskrevet med alder, yrke, navn på institusjon der de ble innlagt og lengde på oppholdet. Hun reiser et begrunnet spørsmål om de noen gang har eksistert, eller om de er mer eller mindre fiktive sammendrag av andre pasienthistorier.

Rosenhan møtte kraftig motbør da artikkelen ble publisert. Det påfølgende nummeret av Science inneholdt 12 sider med kritiske kommentarer. En av kritikerne var Robert Spitzer, som seinere ble hovedforfatter for DSM-III. Spitzer fikk for øvrig - til Rosenhans store misnøye - tilsendt en kopi av sistnevntes journal fra hans behandler på Haverford. Han har derfor trolig visst at Rosenhan tok seg friheter i beskrivelsen av hva som faktisk skjedde før og under innleggelsen. Spitzer holdt imidlertid munn, og Science-artikkelen kunne inngå i begrunnelsen for en ny og kriteriebasert diagnostisk praksis.

\section{Diagnoser eller virkelighet?}

At psykiatere diagnostiserte pasienter på en uetterrettelig og nærmest tilfeldig måte, var pinlig for faget. Det viktigste argumentet for den kriteriebaserte diagnostikken i DSM-III var $\emptyset k t$ reliabilitet. I tillegg hadde man nok et håp om at validiteten skulle bli bedre, altså at det bak beskrevne symptomer skulle finnes mer grunnleggende mønstre eller sammenhenger. Psykiatriske lidelser ble i DSM-systemet forstått og definert som hjernesykdommer, ikke som mentale lidelser, og man håpet at diagnosekriteriene skulle bidra til både forklaring på og behandling av spesifikke sykdommer, som kunne bli bedre forstått etter hvert. Det har så langt ikke skjedd. 


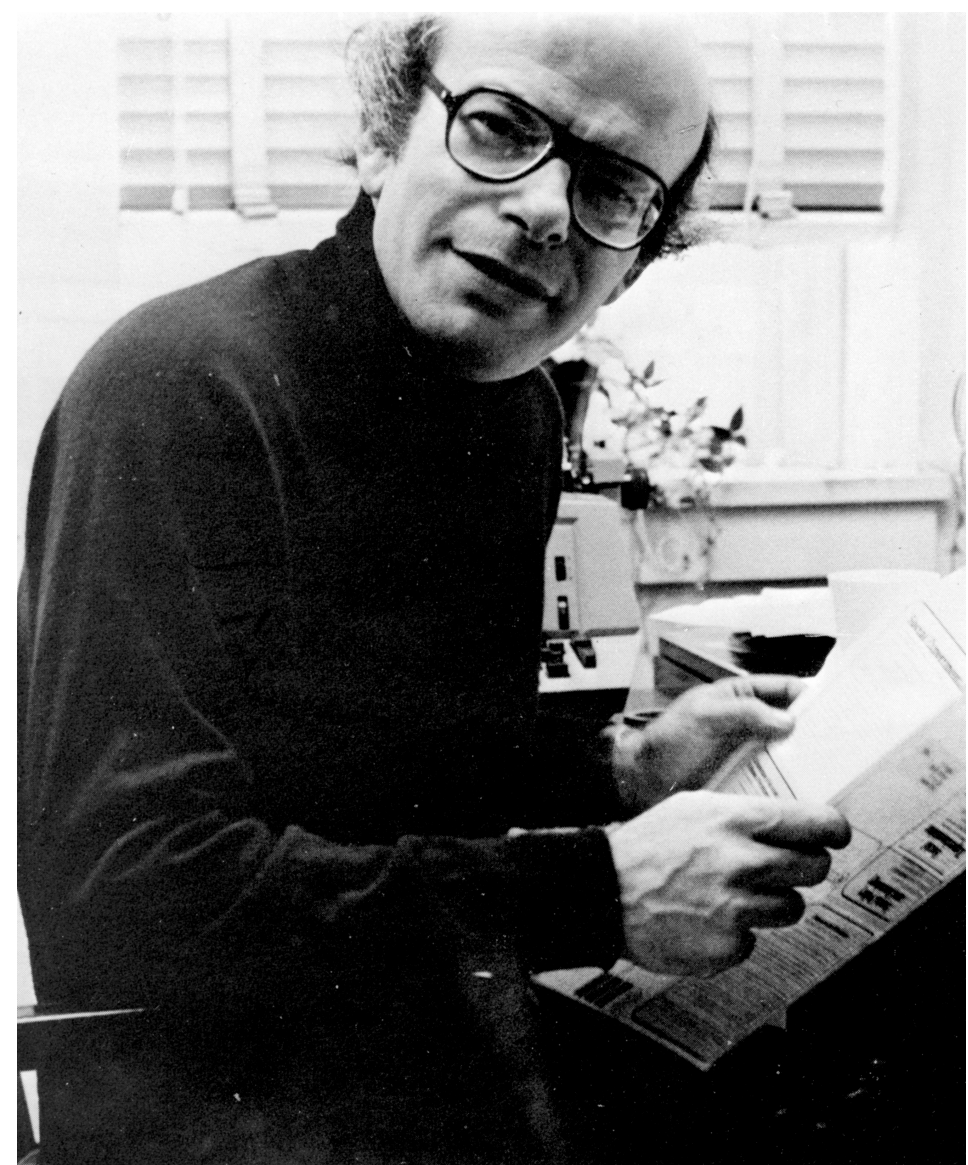

Portrett av David Rosenhan fra Stanfords årbok i 1975. Foto: Stanford university

Utviklingen av DSM-systemet har fått store konsekvenser ut over de rent faglige. Særlig to områder har profittert: forsikringsindustrien har fått klare aksjonsgrenser, og medikamentindustrien er blitt tilført et ekspanderende marked hver gang psykiske påkjenninger og reaksjoner er blitt omdefinert som sykdom.

Prinsippene som ble slått fast i DSM-III, er også i dag gjeldende standard, nå som DSM-5. Europa har innrettet sitt ICD-system, som nå er i sin 11. utgave, etter DSM. DSM-III og etterfølgende versjoner, DSM-IIIR, DSM-IV og DSM-5, innebar en betydelig utvidelse av begrepet psykiatrisk sykdom. Særlig depresjon, bipolar lidelse, ADHD og autismespekterlidelse har fått vide kriterier og har økt kraftig i omfang. DSM-5 har møtt betydelig kritikk, både på grunn av en ytterligere utvidelse av hva som defineres som sykdom og fordi kriteriene har blitt mer uklare (5). Reliabilitet måles vanligvis som Cohens kappa $(\kappa)$, der intervallet fra 1 til o tilsvarer variasjonen fra fullstendig samsvar til ren tilfeldighet. Under utviklingen av DSM-5 ble definisjonen av akseptabel reliabilitet redusert fra en א-verdi på o,6 til o,4 (6). Utviklingen av diagnosesystemene har altså ikke bedret verken diagnostisk konsensus eller treffsikkerhet.

Paradoksalt nok skal det fortsatt ikke mye til for å få en schizofrenidiagnose etter kriteriene i DSM-5

Det ser i hvert fall ut til at schizofrenidiagnosen satt løst i amerikansk psykiatri i tiden rundt 1970. Rosenhans egne og en eller et fåtall medarbeideres erfaringer kan ha overbevist professoren om at han - selv uten å ha gjennomført eksperimentet slik det ble beskrevet i Science - likevel hadde rett. I så måte minner tildragelsen om en annen kjent historie om uetterrettelig forskning: immunologen William Summerlins transplantasjonsforsøk på gnagere. Summerlin påberopte seg - kanskje med rette, mener noen av de som har ettergått historien - initialt suksess med transplantasjoner over artsgrenser uten å se tegn til avstøtningsreaksjoner. Han klarte ikke å reprodusere funnene og grep etter hvert til tusjpennen for å «synliggjøre» vellykkede hudtransplantater for en utålmodig veileder. Avsløringen på vårparten i 1974 ga et sentralt forskningsmiljø ved ærverdige Memorial 
Sloan Kettering Cancer Center stygge riper i lakken (7).

Paradoksalt nok skal det - som i Rosenhans velmaktsdager - fortsatt ikke mye til for å få en schizofrenidiagnose etter kriteriene i DSM-5. Hvis pasienten eksempelvis hører en kommenterende stemme i en måned (eller mindre hvis han får en eller annen form for behandling), er lite motivert, og det foreligger «failure to achieve expected level of interpersonal, academic, or occupational functioning», vil vedkommende oppfylle kriteriene for schizofreni. Det grunnleggende fenomenet ved psykoser er vrangforestillinger, altså en realitetsbrist. Å høre stemmer innebærer ikke nødvendigvis en realitetsbrist så lenge personen er klar over at stemmene ikke finnes i verdenen utenfor, men denne distinksjonen eksisterer ikke i DSM-5. For å få en schizofrenidiagnose er det ikke et krav at pasienten opplever stemmene som virkelige. Det er altså mulig å bli diagnostisert som schizofren uten å være - eller noen gang ha vært - psykotisk.

Cahalan siterer den storvokste og tause indianerhøvdingen Chief Bromden i Gjøkeredet: «It's the truth even if it didn’t happen.» Slik forholder det seg kanskje også med «On being sane in insane places» fra 1973. Og vår beskrivelse og forståelse av galskap er fortsatt utilstrekkelig.

LITTERATUR:

1. Rosenhan DL. On being sane in insane places. Science 1973; 179: 250-8. [PubMed][CrossRef]

2. Kendell RE, Cooper JE, Gourlay AJ et al. Diagnostic criteria of American and British psychiatrists. Arch Gen Psychiatry 1971; 25:123-30. [PubMed][CrossRef]

3. Cahalan S. The great pretender. The undercover mission that changed our understanding of madness. Edinburgh: Canongate Books Ltd., 2020.

4. Cahalan S. Brain on fire. My month of madness. New York, NY: Free Press, 2012.

5. Frances A. Saving normal. An insider's revolt against out-of-control psychiatric diagnosis, DSM-5, big pharma, and the medicalization of ordinary life. New York, NY: Harper Collins, 2013.

6. Kraemer HC, Kupfer DJ, Clarke DE et al. DSM-5: how reliable is reliable enough? Am J Psychiatry 2012; 169:13-5. [PubMed][CrossRef]

7. Broad W, Wade N. Betrayers of the truth. Fraud and deceit in the halls of science. New York, NY:

Simon \& Schuster, 1982.

Publisert: 23. november 2020. Tidsskr Nor Legeforen. DOI: 10.4045/tidsskr.20.0184

(C) Tidsskrift for Den norske legeforening 2020. Lastet ned fra tidsskriftet.no 